\title{
LUTA LIVRE NOS FILMES: CONCEPÇÃO, SIMILARIDADE E JUSTIÇA
}

\author{
Carlos Cesar Domingos do Amaral ${ }^{1}$ (Comunicação e Inovação - USCS)
}

\section{RESUMO}

A Luta Livre é um esporte de entretenimento caracterizado pela mistura de atividade física, espetáculo e teatro, sendo sucesso em diversos países do mundo. Nos Estados Unidos, México e Japão está altamente difundida e caracterizada na cultura do povo. Muitos são os filmes que retratam esta prática e esse artigo se objetiva em conhecer a caracterização da Luta Livre nos mesmos. A escassez de trabalhos sobre a exposição da Luta Livre se justifica nessa concepção. Metodologia se aprofunda em pesquisa documental, revisão bibliográfica como Barthes (1972), DoAmaral (2016), Drago (2007) entre outros. Resultados apontam que os filmes encontrados e analisados buscam contar histórias que podem retratar a realidade, assim como em O Lutador (2008), exploração do humor em Nacho Libre (2006), disputa esportiva em Dois na Lona (1968), animação em Scooby Doo e os mistérios na Wrestlemania (2014). Cada um busca entreter de uma forma, mas o vilão e o herói que são personagens típicos do ProWrestling continuam a serem usados, para que a obra possa prender e satisfazer o público, com o herói vencendo. Propósito de justiça idêntico aos dos combates. Mostrando assim similaridade entre Pro-Wrestling e filmes.

Palavras-chave: Filmes, Luta Livre, Pro-Wreslling.

\section{INTRODUÇÃO}

Atualmente a indústria de filmes com grande produção ou não é algo de fácil acesso nas mais diversas localidades. Só nos cinemas cerca de quatro filmes em média são lançados, além dos curtas já disponíveis pela internet e etc. O caminho do filme que vai para a grande massa é depois ser vendida em plataformas como o Blu-ray, DVD, canais fechados e por fim a TV aberta. Dentro de toda essa indústria um tema precisa ser escolhido para a construção de uma obra e a Luta Livre já foi assunto em diversas obras. Possivelmente alguma delas não seja citada aqui, mas esse artigo é apenas um primeiro dentro desse grande campo.

Mas o que seria Luta Livre? DoAmaral (2016, p. 11 - 12) define:

Esporte de Entretenimento: Prática esportiva que mistura ações do teatro e espetáculo em busca de levar entretenimento aos espectadores. Os resultados são determinados nos bastidores, os participantes e a empresa sabem o que irá acontecer, os fãs não. Os praticantes precisam ser atletas, pois o esforço físico é alto. Os riscos de integridade física são os mesmos que qualquer outro esporte. Objetos cortantes, cadeiras, escadas, mesas e até mesmo fogo podem ser

\footnotetext{
${ }^{1}$ Mestre em Comunicação na Universidade São Caetano do Sul - USCS. Jornalista pela Universidade de Uberaba (UNIUBE), Especialista em Jornalismo Esportivo e Negócios do Esporte pela FMU Faculdades Metropolitanas Unidas. carlaomestre@hotmail.com
} 


\section{SEMINÁRIO DE PESQUISA EM CIÊNCIAS HUMANAS - SEPECH \\ Humanidades, Estado e desafios didático-científicos \\ Londrina, 27 a 29 de julho de 2016}

usados na busca de maior adrenalina. O local para as exibições podem ser o ringue, tatame ou qualquer outro espaço como garagens, jardins, parques e etc (DOAMARAL, 2016, p. $11-12$ ).

O objetivo desse trabalho é contar quais são os filmes que retratam a Luta Livre e como a obra trata o tema, isso porque as formas de se aplicar os fundamentos desse Esporte de Entretenimento são as mais diversas. Além de compreender se o ato de fazer justiça é cumprido. Justifica-se esse trabalho pelo número insuficiente de trabalhos ligados a esse esporte na América Latina.

Para Barthes (1972, p. 11) os fãs interagem com muito entusiasmo a Luta Livre. "Entrega-se à primeira virtude do espetáculo: abolir qualquer motivo ou consequência; o que lhe interessa é o que se vê, e não no que crê" (BARTES, 1972, p. 11). Isso se dá para que quem estiver assistindo possa se divertir, extravasar e escapar da rotina do dia a dia durante toda a ação. O autor ainda conta que o propósito da Luta Livre é fazer justiça, pois os lutadores heels (os vilões) sempre usam de artimanhas para buscarem a vitória e isso vai totalmente contra os valores defendidos pelos babyfaces ou faces (os mocinhos) que se dedicam a buscar seus objetivos de forma limpa. Dessa forma a rivalidade nasce e enquanto o vilão busca trapacear, o herói luta pelo que é certo. Ao final de um grande combate o mocinho vence e assim cumpre a justiça desse esporte. Isso tudo nada mais é do que a "jornada do herói" na qual o protagonista é injustiçado, exonerado, machucado para que ao fim possa encontrar seu rival e ocorrer um ajuste de contas. Esse tipo de enredo é trabalhado nos seriados, filmes, novelas, teatro e etc. A diferença é que na Luta Livre o herói também pode perder, ou para prolongar a rivalidade ou para que os personagens mudem de foco na ambição da empresa.

Por buscar apenas o entretenimento, no Brasil ficou conhecida como "marmelada". "No Brasil, o catch foi intensamente difundido, a partir da década de 1960 pela televisão quando passou a ser conhecido com Telecatch" (DRAGO, 2007, p. 16). Esse nome se dá da junção de duas palavras Tele de Televisão e Catch de Catch-ascatch-can que é um dos primeiros estilos de Luta Livre existentes. "O Telecatch é o esporte de quem gosta de praticar uma atividade física simplesmente por esporte"! (DRAGO, 2007, p. 13 - 16). Mesmo os brasileiros vivendo a cerca de inúmeras ficções diárias, os mesmos não aceitam que esse esporte também trabalhe isso.

\section{METODOLOGIA}

Essa pesquisa lida com revisão bibliográfica com as obras sobre Luta Livre de DoAmaral (2016), Barthes (1972) e Drago (2007). Pizzani et al (2012, p. 54) afirma "pesquisa bibliográfica é a revisão da literatura sobre as principais teorias que norteiam o trabalho científico. (...) Pode ser realizada em livros, periódicos, artigo de jornais entre outras fontes" (PIZZANI et al, 2012, p. 54). Além da pesquisa documental para se encontrar o maior número de filmes possível, principalmente aqueles que não foram veiculados no Brasil. Esse método "vale-se de documentos originais, que ainda não receberam tratamento analítico por nenhum autor [...] é uma das técnicas decisivas para a pesquisa em ciências sociais e humanas" (HELDER, 2006, p. 1-2 apud SÁ-SILVA et al, 2009, p. 3). 


\section{SEMINÁRIO DE PESQUISA EM CIÊNCIAS HUMANAS - SEPECH \\ Humanidades, Estado e desafios didático-científicos \\ Londrina, 27 a 29 de julho de 2016}

\section{OS FILMES SOBRE LUTA LIVRE}

\subsection{Dois na Lona (1968)}

Esse é o único filme brasileiro que trata do tema. O lutador Ted Boy Marino e Renato Aragão são os protagonistas da obra. No enredo eles são dois mecânicos e acabam desenvolvendo namoro com duas primas ricas. A que namora Ted Boy acaba sendo sequestrada, tudo isso para que ele entregue a luta frente ao seu adversário na final de um campeonato de Luta Livre. Enquanto o lutador sofre nas mãos de seu rival que é protegido pela arbitragem, Renato e outras pessoas vão investigando o paradeiro da moça. Após seguir alguns dos bandidos é encontrado o local onde está lá. Com direito a muitas brincadeiras de Renato Aragão, eles conseguem salvar a moça. Ao retornarem ao local da luta, Ted Boy já tinha apanhado bastante nos nove primeiros rounds. Para que ele vencesse era necessário finalizar o adversário nos próximos dois. No último round, Ted faz uma chave dupla nos braços do rival que se entrega. Ted Boy Marino é dado como campeão de Luta Livre. $O$ filme se encerra nessa mesma cena, mas ao que dar a entender é que os relacionamentos dos casais seguirão e tendo um esportista na família.

Nesse filme, a Luta Livre aparece como o esporte que rende bastante dinheiro de apostas, esse foi o motivo do sequestro da namorada de Ted Boy. Além de que os vilões serem dois nessa obra, o sequestrador e o lutador da final do torneio. Ambos buscavam o que queriam sem pensar no bem estar dos outros. Assim o vilão que não lutava foi vencido por um herói sem prática de combate, enquanto Ted Boy Marino mostrou dentro do ringue do porque ser o melhor atleta da modalidade. Essas duas vitórias fizeram a justiça de forma explícita, assim como a Luta Livre retrata.

\subsection{Nacho Libre (2006)}

A Luta Livre tem a faceta de usar o humor em suas histórias, mas isso também significa que esta não seria o enredo principal de uma empresa. Visto que as risadas poderiam não trazer o lucro desejado.

Aqui em Nacho Libre isso não é lei, pois todo o enredo é de humor. A história conta a vida de Ignácio que era um rapaz pobre e que vivia em um monastério, fã de Luta Livre, mas que sempre via os administradores do local onde morava repreender esse esporte por ser muito violento. Isso não fez Ignácio deixar de sonhar em ser um lutador famoso. Irmã Encarnación é uma mulher que ajuda a cuidar dos órfãos que moram nesse mesmo lugar, Ignácio se apaixona por ela. O monastério passa por dificuldades financeiras e isso encoraja ao protagonista buscar o sonho de lutar, no início sua vestimenta é simples e a falta de destreza é algo notório, principalmente por estar fora de forma. De derrota em derrota ele ganha um pouco de dinheiro junto de um amigo que é seu companheiro de dupla. Depois de um mal entendido em uma festa, $E l$ Nacho (o nome de lutador de Ignácio) acaba sujando um lutador com bebida, o mesmo fica enfurecido e o desafia a lutar, caso ele ganhe fica com o cinturão. Nacho aceita o desafio. Todos já esperam um massacre no ringue e é bem isso que acontece em boa parte da luta, no final o herói vê todo o monastério torcendo por ele na arquibancada, 


\section{SEMINÁRIO DE PESQUISA EM CIÊNCIAS HUMANAS - SEPECH \\ Humanidades, Estado e desafios didático-científicos \\ Londrina, 27 a 29 de julho de 2016}

aquilo o anima e o faz dar uma reviravolta na luta. Após um salto de uns 15 metros aproximadamente, ele acerta o vilão e o vence, se tornando em campeão. $O$ título lhe rende dinheiro, o monastério volta a prosperar e até um ônibus Nacho compra para carregar os órfãos. A paixão dele por Encarnácion fica deixada em mistério, mas ela sempre fica sem jeito quando está perto dele.

A Luta Livre aqui mesmo que retratada por um herói engraçado não deixa de mostrar que é possível se alcançar a glória se você acredita em si mesmo. Nacho Libre traz um lutador que pouco saber fazer dentro de um ringue, mas por lutar por algo maior do que ele, o inesperado acontece. Toda essa volta por cima dá ao espectador animação que também é possível chegar ao topo. Para quem pouco conhece Luta Livre, um filme assim pode dar uma oportunidade de se divertir e daí nascer o interesse de compreender melhor esse mundo. Essa história mesmo contada com humor é inspirada no padre Frey Tormenta que fazia Luta Livre em mistério para trazer dinheiro ao seu monastério.

\subsection{WWE - Scooby Doo Wrestlemania Mistery (2014)}

A animação da WWE - World Wrestling Entertainment junto da equipe da máquina mistério fica em torno do maior evento de Luta Livre do mundo, a Wrestlemania. Scooby e seus amigos vencem um torneio de vídeo game da WWE e recebem a oportunidade de conhecer a fictícia WWE City. Ao chegarem por lá conhecem diversos personagens reais da equipe e outros criados apenas para o filme. Um monstro aparece e coloca o cinturão principal como seu objetivo de roubo. Tudo é feito para que isso não ocorra, mas após passar por uma hipnose, Scooby rouba o cinturão. Ele é dado como culpado pelas imagens das câmeras e também por estar dormindo com o objeto. A investigação começa aí e se descobrem que o título encontrado com o cachorro é falso, o verdadeiro já tinha sido roubado. Para provarem inocência, Scooby e Salsicha são obrigados a enfrentarem Kane em uma luta sem regras. Eles ficam fugindo do lutador ao redor do ringue. Enquanto isso, Velma, Fred e Daphne montam uma armadilha para o monstro que aparece na Wrestlemania. Algo dá errado e o monstro fica preso de uma jaula junto de Scooby, Salsicha, Kane, John Cena, Sin Cara e um jovem que sonhava ser lutador. Após muita força para derrubar o vilão, resta ao protagonista pular da terceira corda e com o impacto estragar a máquina / monstro. O culpado é o pai do jovem lutador, o filho fica chocado com o acontecido. A WWE diz a ele que se o sonho dele é lutar, as portas estarão abertas e ele aceita. No fim da Wrestlemania, Scooby e Salsicha são coroados como os Campeões da WWE.

Nessa obra a Luta Livre é o foco central, tudo é relacionado à WWE. Muito daquilo é fictício, mas em nenhum momento se está fora do tema. Pelo herói não ser um lutador não quer dizer que o objetivo não foi alcançado, pelo contrário, o vilão foi vencido dentro do ringue com golpes característicos da modalidade e toda a apreensão até o desfecho final se mostrou idêntica ao feito nos combates reais.

\subsection{Os Flintstones e as Estrelas do WWE (2015)}

No ano seguinte a WWE voltou a fazer uma animação, dessa vez na era da pré história. Fred Flintstone busca a oportunidade de ganhar dinheiro fácil, pois o tempo na pedreira não está rendendo muito. Além de que está chegando o aniversário de 


\section{SEMINÁRIO DE PESQUISA EM CIÊNCIAS HUMANAS - SEPECH \\ Humanidades, Estado e desafios didático-científicos \\ Londrina, 27 a 29 de julho de 2016}

casamento e ele quer impressionar Wilma. Ele tenta primeiro o boliche, mas não dá certo, ele então "cria" a Luta Livre. Sua empresa é a FFE - Fred Flintstone Entertainment. O evento atrai a população, mas os lutadores não sabem muito o que fazer e realizam as lutas com muita rapidez, assim o público começa a sentir enganado. CM Punk que nesse período era funcionário da WWE interpretou o vilão e com suas malvadezas deixou Barney irritado por amedrontar seu canguru e por ficar fazendo brincadeiras com a altura dele. É decidido que os dois irão lutar, após um começo ruim para o vizinho de Fred, o mesmo se recupera e vence o lutador. $\mathrm{O}$ povo vai à loucura. No final Fred vende a empresa para Vince McMahon (Presidente da WWE) por achar difícil a rotina de espetáculos.

A Luta Livre aqui é mostrada também como entretenimento, mas o foco principal é fazer o vilão CM Punk pagar por todos os seus atos ruins durante o filme. Isso acaba acontecendo no final. Outros pontos a serem abordados são o pouco conhecimento de como desenvolver as lutas, pois a ideia a se passar é que ela acabou de ser criada.

\subsection{Nossa Luta - To The Mat (2011)}

Esse filme conta a história de uma consultora que foi contratada para salvar uma academia de Luta Livre da falência. Janice Bailor não conhece nada do esporte, mas sabe sobre negócios. Ela conhece a equipe e o cenário da empresa em um show ao vivo. Tudo aquilo é estranho, principalmente a "selvageria" do público e lutadores. Aaron Slocum é o herdeiro da empresa, mas quem contratou Janice foi sua mãe, uma senhora que teme em perder o legado criado por seu falecido esposo. Aaron faz de tudo para que Janice desista e volte para a capital americana, mas ela persistiu em ajudar. O noivado dela junto a um empresário começa a enfraquecer, pois ele não tem paciência em ouvila ou gosto pelo esporte. A protagonista se acostuma com o ambiente do interior americano e o tempo faz com que ela e Aaron desenvolvam um relacionamento. Ela abandona suas funções na capital e junto do novo namorado administram a equipe que paga todas as dívidas.

A obra é uma comédia romântica e o Pro-Wrestling fica como o problema a ser resolvido, pois a equipe é pequena e os devedores são muitos, com a experiência da Janice, os negócios se acertam. Além disso, é mostrado como os lutadores de uma mesma equipe são amigos, sendo suas representações de vilões e heróis deixadas apenas para os shows.

\subsection{Prontos para Detonar - Ready to Rumble (2000)}

Essa foi uma realização da extinta equipe WCW - World Champhionship Wrestling. Na obra os fãs de Luta Livre, Gordie e Sean vão a um dos shows da empresa, o WCW Monday Nitro para torcerem pelo ídolo Jimmy King. Nos bastidores da equipe, King é traído pelo novo manager e após um ataque brutal de vários lutadores perde o cinturão e seu emprego. Os protagonistas vão à busca da casa de King para ajudá-lo a reconquistar o trabalho e o título. As cenas trabalham o humor e após recuperar a forma do lutador, eles voltam a WCW e aparecem de surpresa ao vivo. Eles pedem uma 


\section{SEMINÁRIO DE PESQUISA EM CIÊNCIAS HUMANAS - SEPECH \\ Humanidades, Estado e desafios didático-científicos \\ Londrina, 27 a 29 de julho de 2016}

revanche e com a multidão em festa é impossível de ser negada. A luta acontece no evento principal, à estipulação é chamada os "três estágios do inferno". São quatro jaulas, uma maior ao redor do ringue e as outras três sobre o mesmo, o que conseguir chegar ao topo da última e retirar o cinturão do gancho vence. King e seus amigos apanham muito, pois o manager usa diversas trapaças. Então surge o lutador Sting, um dos maiores nomes da empresa, assim como de todo o Pro-Wrestling. Ele ajuda King no último estágio e Jimmy King recupera o campeonato.

Neste filme a Luta Livre busca a mística de que mesmo nos piores momentos podemos contar com as pessoas, nesse caso os fãs. Sem eles King jamais teria tido a coragem de se levantar. Os valores do renascimento da atitude de campeão e a amizade são os focos principais do enredo. Em certo ponto até se comenta do Pro-Wrestling ser um show, mas durante os treinamentos se nota a veracidade do esporte. O maior erro da WCW foi após o filme fazer com que o autor que interpretou King em um campeão mundial da empresa (WCW World Heavyweight Champhion) isso acabou com a magia do filme e decretou a falência da equipe. A WWE a comprou.

\subsection{O Lutador - The Wrestler (2008)}

Mickey Rourke é Randy “O Carneiro” Robinson. Ele é uma das grandes estrelas do cenário independente da Luta Livre. O sucesso dos ringues não lhe rende uma vida de riqueza, sua moradia é em um trailer. Após um evento Randy desmaia, após os exames o médico lhe diz que mais um desmaio desses e ele morrerá por causa das contusões e hábitos na carreira como lutador. Ele então decide se aposentar e se reaproximar da filha com quem não fala faz muito tempo. O contato é difícil e quando tudo parece dar certo entre os dois, Randy fica bêbado e não vai ao jantar da filha. As relações entre eles estremecem e ela desiste do pai. Durante esses acontecimentos, Randy se envolve com uma prostituta e seu jovem filho. Esse contato o faz querer ajudar os dois e ele volta a lutar, pois o mais importante agora é estar entretendo o povo com suas manobras, se isso o vai levar ao óbito, aparentemente não importa. Ele volta a usar anabolizantes, pintar o cabelo, bronzeamento artificial, musculação e etc. Ao ver os fãs ele agradece a todos por acompanhar suas lutas. O combate acontece e no final ele sobe na terceira corda e pula com os braços dobrados simbolizando os chifres do carneiro, se escuta o contar de um, dois e três do público com o som diminuindo e dessa forma acaba o filme.

A Luta Livre é aplicada como o que pode acontecer no cenário independente, pois o dinheiro nesse setor é bem baixo. Assim o ato de heroísmo de Randy é concluído com a volta as lutas para ajudar sua namorada, mas ele falha com o contato com sua filha. Seria a forma de dizer "não se pode vencer todas". Em relação ao Pro-Wrestling a obra mostra que a ação vai sempre existir, mas a riqueza é algo para poucos. A forma de se mostrar que fora do espetáculo, a vida continua a ser difícil é o ponto real do filme. $\mathrm{O}$ vilão aqui não é uma pessoa, mas sim as nossas escolhas e atitudes. Como obra é a que mais apresenta o lado fora do espetáculo e glamour da Luta Livre. 


\title{
XI SEMINÁRIO DE PESQUISA EM CIÊNCIAS HUMANAS - SEPECH \\ Humanidades, Estado e desafios didático-científicos \\ Londrina, 27 a 29 de julho de 2016
}

\subsection{Garotas Duras na Queda - ... All The Maribles (1981)} enredo:

Poucas são as cenas encontradas desse filme, mas WrestleBR (2016a) explica o

\begin{abstract}
Molly e Iris formam a dupla de lutadoras conhecidas como California Dolls, duas lindas mulheres que junto de seu empresário, Harry, atravessam os Estados Unidos à procura de um ringue para lutar e alcançar fama no circuito de wrestling. Além de diversas dificuldades pelo caminho e pequenos problemas de relacionamento entre os três, a dupla ainda tem de enfrentar o assédio dos promotores e também do público, que estão mais a fim de ver o corpo do que a técnica das lutadoras. As California Dolls tentam mostrar que são muito mais do que um par de rostos bonitos, demonstrando suas habilidades luta após luta, e assim, provando que merecem uma chance de conquistar o maior título de tags do wrestling feminino mundial por seus próprios esforços (WRESTLEBR, 2016a).
\end{abstract}

Analisando a partir desse relato é visto como é difícil para as mulheres obterem o espaço na Luta Livre. Em uma das poucas cenas que encontrei, as protagonistas foram chamadas para fazer uma luta na lama para entreter os homens. Não posso confirmar se elas aceitaram fazer por U\$500,00. Contudo os pontos a se destacarem é que existem inúmeras mulheres excelentes em Pro-Wrestling, o preconceito vem sido combatido por elas, pois participam de grandes eventos e equipes.

\subsection{A Taberna do Inferno - Paradise Alley (1978)}

WrestleBR (2016b) conta que:

O filme conta a história dos Irmãos Carboni, três descendentes de italianos tentando vencer o verdadeiro inferno que é viver em Hell's Kitchen, ambientado nos anos 40. (...) Temos Stallone como Cosmo, um sujeito que através de sua lábia tenta correr atrás de seus sonhos. A "malandragem" de Cosmo o leva e seus irmãos para o clube clandestino conhecido como Paradise Alley. (...) Além de ser um reduto de criminosos, bêbados, jogadores e afins, o clube tem como atração o desafio de wrestling contra o campeão local. Cosmo Carboni vê ali uma chance de largar a pobreza de uma vez por todas, e assim, se torna treinador do seu irmão Victor, que agora é conhecido como o lutador "Kid Salami". Lenny também acaba se envolvendo e tornando-se empresário de Victor, e pouco a pouco acaba perdendo seus valores quando se depara com o sucesso de seu irmão no mundo das lutas (WRESTLEBR, 2016b).

Esse deve ser o único filme de Stallone junto do Pro-Wrestling, o esporte aqui foi contado como a forma de escapar da pobreza, a vilania existe dentro e fora do ringue. Aos protagonistas restam vencer primeiro dentro da arena para depois pensar no 


\title{
XI SEMINÁRIO DE PESQUISA EM CIÊNCIAS HUMANAS - SEPECH \\ Humanidades, Estado e desafios didático-científicos \\ Londrina, 27 a 29 de julho de 2016
}

cotidiano. Ao que parece, os dois resultados foram alcançados para que assim a justiça possa ter sido realizada, os heróis exaltados e os malfeitores vencidos.

\subsection{Grunt - Confronto Mortal / Grunt! The Wrestling Movie (1985)}

Mais um filme com poucos minutos encontrados, assim WrestleBR (2016b) afirma:

\begin{abstract}
“Mad Dog" Joe de Curso era uma lenda, com uma enorme legião de fãs e uma imensa popularidade nos ringues. Porém, tudo foi por água abaixo após uma luta pelo cinturão contra Skull Crusher Johnson, em 1979. A luta estava emparelhada, até Skull Crusher ficar preso nas cordas e Mad Dog, acidentalmente, decapitar seu oponente com um golpe (...) Você chega a acreditar em certos momentos que toda essa história realmente aconteceu, por ser criada uma atmosfera realística de um documentário (WRESTLEBR, 2016b).
\end{abstract}

Segundo esses relatos, o acidente fatal é o ponto chave do filme, o que sem dúvida faz parte da Luta Livre. Muitos foram os lutadores que perderam suas vidas ou que sofreram acidentes que deixaram os mesmos em cadeiras de rodas. Quem odeia o Pro-Wrestling sempre dirão que tudo é falso, mas a ação dentro do ringue é muito real e acidentes acontecem, mesmo com os inúmeros treinos de execuções, algo pode dar errado.

\subsection{Além do Ringue - Beyond the Mat (1999)}

Esse filme caminha pelas vertentes do documentário. WrestleBR (2016b) analisa a exposição da Luta Livre no mesmo:

O foco principal de Além do Ringue fica mesmo com os lutadores e seus dramas pessoais, mostrando que os atletas que tanto idolatramos são seres humanos normais tanto quanto nós. O documentário abre um paralelo entre dois pontos de vistas muito distantes: o dos fãs, alienados somente ao que acontece dentro dos ringues, e o da família dos lutadores, com sua preocupação constante com o antes, durante e depois de cada luta. Em uma das cenas mais impactantes do filme, durante a "I Quit Match" entre The Rock e Mankind no Royal Rumble 1999, vemos o desespero no olhar da mulher e dos filhos de Mankind a cada cadeirada que o lutador levava na cabeça, algo que um espectador normal nunca iria imaginar (WRESTLEBR, 2016b).

Aqui os problemas enfrentados por Randy em O Lutador (2008) são demonstrados na vida de lutadores renomados. Que o espetáculo é lindo, mas o dia a dia é o mais complicado possível. Que o heroísmo fica nas lutas e que para arrumar as questões diárias é necessário ainda mais empenho. Por fim as dificuldades com as lesões que podem encerrar vidas. 


\section{SEMINÁRIO DE PESQUISA EM CIÊNCIAS HUMANAS - SEPECH \\ Humanidades, Estado e desafios didático-científicos \\ Londrina, 27 a 29 de julho de 2016}

\section{PRODUÇÕES MEXICANAS}

O México é um dos grandes cenários da Luta Livre ou Lucha Libre como eles mesmos falam. Assim inúmeros foram os filmes criados para que seus luchadores mostrassem o quanto eram heróis de verdade e não fictícios como a maioria é. Fuego en el Ring (2006) traz diversos títulos criados ${ }^{2}$.

O número de obras chega a assustar, principalmente por apenas o primeiro não ter sido focado nos lutadores El Santo, Blue Demon e Mil Máscaras, os demais sempre usaram os três ou pelo menos um. A forma de construção da exposição da Luta Livre era focada nos lutadores citados, em vilões que também lutavam e também em monstros que após levarem os golpes iriam enfraquecendo até serem vencidos. Essa foi a forma encontrada para que os lutadores pudessem combater vilões humanos, ou seja com o ato de lutar mesmo, chutes, socos, pontapé, voadoras e muita plástica nos golpes, algo que é da cultura mexicana. Isso fazia com que as pessoas vissem os verdadeiros heróis. Com o tempo foi entendido que eles também poderiam "salvar o mundo" e os monstros também receberam a oportunidade de serem derrotados. Entre os humanoides estão zumbis, alienígenas, vampiros, fantasmas, múmias e etc. Santo e Blue Demon é a maior rivalidade existente na Lucha Libre mexicana, nos filmes eles também já foram rivais, assim como parceiros para vencer o mal.

2 La Bestia Magnifica (1952); Santo contra el Cerebro del Mal (1958); Santo contra los Hombres Infernales (1958); Santo contra los Zombies (1961); Santo contra el Rey del Crimen (1961); Santo en el Hotel de la Muerte (1961); Santo contra el Cerebro Diabólico (1962); Santo vs las Mujeres Vampiro (1962); Santo en el Museo de Cera (1963); Santo vs el Estrangulador (1963); Santo contra el Espectro (1963); Blue Demon contra el Poder Satánico (1964); El Hacha Diabólica (1964); Atacan las Brujas (1964); Profanadores de Tumbas (1964); El Barón Brákola (1965); Santo, el Enmascarado de Plata vs la Invasión de los Marcianos (1966); Santo, el Enmascarado de Plata vs los Villanos del Ring (1966); Operación 67 (1966); El Tesoro de Moctezuma (1966); La Sombra del Murciélago (1966); Arañas Infernales (1966); Blue Demon vs. Cerebros Infernales (1966); Blue Demon contra las Diabólicas (1966); Blue Demon, Destructor de Espías (1967); Blue Demon en Pasaporte a la Muerte (1967); Blue Demon y las Invasoras (1968); Santo en el Tesoro de Drácula (1968); Santo contra Capulina (1968); Santo contra Blue Demon en la Atlántida (1969); Santo y Blue Demon contra Los Monstruos (1969); El Mundo de los Muertos (1969); Santo vs Los Cazadores de Cabezas (1969); Santo Frente A la Muerte (1969); Santo en la Venganza de las Mujeres Vampiro (1970); Santo contra Los Jinetes del Terror (1970); Santo vs la Mafia del Vicio (1970); Santo en la Venganza de la Momia (1970); Las Momias de Guanajuato (1970); Los Campeones Justicieros (1970); Santo contra Los Asesinos de Otros Mundos (1971); Santo vs la Hija de Frankenstein (1971); Misión Suicida (1971); Santo y el Águila Real (1971); La Invasión de los Muertos (1971); Santo contra la Magia Negra (1972); Santo y Blue Demon contra Drácula y el Hombre Lobo (1972); Las Bestias del Terror (1972); Anónimo Mortal (1972); Santo contra Los Secuestradores (1972); Santo vs las Lobas (1972); Noche de Muerte (1972); La Mafia Amarilla (1972); Vuelven los Campeones Justicieros (1972); Los Vampiros de Coyoacán (1972); Santo y Blue Demon contra el Doctor Frankestein (1973); Santo contra el Doctor Muerte (1973); Triunfo de los Campeones Justicieros (1973); Santo en el Misterio de la Perla Negra (1974); La Venganza de la Llorona (1974); El Hijo de Alma Grande (1974); Santo en Oro Negro (1975); La Mansión de las Siete Momias (1975); México de Mis Amores (1976); Misterio en las Bermudas (1977); Santo en la Frontera del Terror (1979); Chanoc y el Hijo del Santo vs Los Vampiros Asesinos (1981); Santo contra el Asesino de la Televisión (1981); El Puño de la Muerte (1982); La Furia de Los Karatecas (1982); La llave Mortal (1989); Blue Demon el Campeón (1989); La Revancha (1991); Santo, el Enmascarado de Plata (1992); Atlantis al Rescate (2008) (FUEGO EN EL RING, 2006). 


\section{SEMINÁRIO DE PESQUISA EM CIÊNCIAS HUMANAS - SEPECH \\ Humanidades, Estado e desafios didático-científicos \\ Londrina, 27 a 29 de julho de 2016}

\section{RESULTADOS}

Após analisar todos esses filmes é notório que poderiam ser divididos em animações e obras com autores, pelo gênero humorístico, aventura e etc. Prefiro que sejam compreendidos em Entretenimento e Realidade. No entretenimento ficariam Nacho Libre, Dois na Lona, Prontos para Detonar, as produções mexicanas e as animações da WWE, pois o objetivo deles é levar ao espectador a se motivar para lutar por seus sonhos. Os ligados a realidade mostram que existe muito mais além do espetáculo, preconceito, dores, problemas pessoais, acidentes e mortes. Aqui o fã é introduzido ao mundo normal, na qual dois são os caminhos a serem escolhidos: desistir de algo importante para si mesmo ou acreditar que mesmo após tudo é possível comemorar. O Lutador, Garotas Duras na queda, Além do Ringue e Grunt são as obras dessa categoria.

\section{CONSIDERAÇÕES FINAIS}

A Luta Livre mostra a justiça de o herói vencer o vilão que sempre usa das maldades para conseguir o que quer. Os filmes citados trabalham significados de honra, dedicação, força de vontade e amizade como fatores que comprovem que o mocinho merece a reviravolta e vencer. Não importa se são em desenhos ou com atores, as obras que retratam o Pro-Wrestling tentam levar aos seus fãs que se escolher um caminho ruim, mais cedo ou mais tarde ele se arrependerá. Se ele escolher o bem então com muita dedicação a vitória acontece.

Os diversos formatos de abordagem foram apontados e fica-se notório entender o que motiva os mocinhos e vilões se enfrentarem. Acontece em Nacho Libre de o vilão ser a falta de destreza do protagonista, mas é um filme de comédia, então é algo de se esperar. Nas animações da WWE com Scooby Doo e os Flintstone, a Luta Livre fica como o setor onde se desenrola a história, o que a coloca em um patamar maior por ser o impacto totalitário do enredo. Se não forem solucionados os mistérios a prática seria "arruinada". Ao fim dessa análise compreendo que a forma que são construídos os filmes nessa temática é para dar ao espectador a oportunidade de fugir do cotidiano e de recarregar as energias para continuar a sua própria luta. Além de ressaltar que a beleza está no espetáculo e a vida continua a mostrar problemas para todos. A Luta Livre mostra que até o mais improvável herói pode fazer o impossível.

\section{REFERÊNCIAS}

BARTHES, Roland. Mitologias. Trad. Rita Buongermind e Pedro de Souza. - São Paulo: Difusão Européia do Livro. 1972.

DOAMARAL, Carlos Cesar Domingos. Luta Livre: Esporte de Entretenimento, WWE e Outras Plataformas. Alemanha: Novas Edições Acadêmicas, 2016.

DRAGO. Telecatch: Almanaque da Luta Livre. São Paulo: Vozes, 2007. 


\section{SEMINÁRIO DE PESQUISA EM CIÊNCIAS HUMANAS - SEPECH \\ Humanidades, Estado e desafios didático-científicos \\ Londrina, 27 a 29 de julho de 2016}

PIZZANI, Luciana et al. A arte da pesquisa bibliográfica na busca de conhecimento. In: Revista Digital de Biblioteconomia e Ciência da Informação, Campinas, v.10, n.1, p. 53-66, jul./dez. 2012. Disponível em: <http://goo.gl/ebs0kH> Acesso em: 01 maio 2014.

SÁ-SILVA, Jackson Ronie et al. Pesquisa documental: pistas teóricas e metodológicas. In: Revista Brasileira de História \& Ciências Sociais, v. 1, n. 1, p. 1-15, [S.1.]: 2009. Disponível

em: $<\mathrm{http}$ //www.unisc.br/portal/upload/com_arquivo/pesquisa_documental_pistas_teoricas _e_me todologicas.pdf> Acesso em: 03 dez. 2014.

\section{Pesquisa Documental}

FUEGO EN EL RING. [S.1.]: 2006. Disponível em: $<$ http://www.fuegoenelring.com/hl_fueradelring.php> Acesso em: 12 abr. 2016.

WRESLTEBR. [S.1.]: 2016a. Disponível em: <http://wrestlebr.com/os-melhores-filmessobre-luta-livre-parte-1/> Acesso em: 15 abr. 2016.

WRESLTEBR. [S.1.]: 2016b. Disponível em: <http://wrestlebr.com/os-melhores-filmessobre-luta-livre-parte-2/> Acesso em: 15 abr. 2016. 